\title{
Secretion of angiopoietin-like 4 protein from intestinal cells
}

\section{Soren Drud Nielsen, Randi Jessen, Trine Kastrup Dalsgaard, Jette Feveile Young*}

Department of Food Science, Aarhus University, Denmark

*Corresponding author: Jette Feveile Young, Department of Food Science, Aarhus University Research Centre Foulum, DK-8830 Tjele, PO Box 50, Denmark

Submission date: October 30, 2014; Acceptance date: February 10, 2015; Publication date: February 15, 2015

\begin{abstract}
Background: Angiopoietin-like 4 (ANGPTL4) has been suggested to play a role in lipid metabolism as a regulatory protein of lipoprotein lipase activity. Intestinal secretion of ANGPTL4, which is regulated by fatty acids, may inhibit the activity of circulating lipoprotein lipase; but, recent studies suggest that it could also inhibit pancreatic lipase in the gut and thereby reduce intestinal uptake of lipids. Secretion of the ANGPTL4 protein to either the lumen or tissue/blood side of the intestinal epithelial layer would indicate possible modes of action.
\end{abstract}

Methods: Caco-2 cells were grown on permeable membranes and cultured for 21 days to spontaneously differentiate into an intact monolayer of intestinal cells, mimicking the epithelial cell layer lining the intestinal wall. Cells were treated with $9 \mathrm{mM}$ butyrate and the time dependent gene expression and protein secretion to the apical and basolateral side was analysed over a time-course of 24 hours. Possible feedback from ANGPTL4 protein was investigated by adding $0.25 \mathrm{ng} / \mathrm{ml}$ recombinant ANGPTL4 protein to culture media.

Results: Butyrate-induced ANGPTL4 gene expression increased in Caco-2 cells after 2 hours, reaching a plateau of approximately 6 fold after 6-24 hours, while the ANGPTL4 protein secretion to both the apical and basolateral sides was increased 18-24 hours after stimulation. A negative feedback on apical and basolateral secretion was observed in the presence of recombinant ANGPTL4 on the apical and basolateral sides, respectively.

Conclusion: The present study indicates that, upon exposure to butyrate, the monolayer of epithelial cells secretes the ANGPTL4 protein to both the tissue/blood (basolateral) side and the luminal (apical) side of the monolayer which, in an in vivo situation, may be interpreted as potential inhibition of both the circulating and pancreatic lipase.

Keywords: Angiopoietin-like 4, Caco-2, Permeable membrane, Protein, Secretion, Intestine, Negative feedback. 


\section{BACKGROUND:}

A diet with excess calorie intake combined with physical inactivity contributes significantly to the increased incidence of obesity in the industrialised world [1]. Intake of especially saturated fat has been associated with increased risk of obesity-related metabolic diseases $[1,2]$. However, results from epidemiological studies [3,4] have not been consistent, suggesting a more complex mechanism [5]. Hence, there has been an increasing interest into the pathways involved in lipid metabolism.

More than a decade ago, angiopoietin-like 4 (ANGPTL4) was found to play a role in the lipid metabolism and this protein was abundantly expressed in the liver, fat and intestinal tissues [6]. ANGPTL4 is a regulatory protein of lipoprotein lipase (LPL) activity [7, 8]. It suppresses the clearance of circulating triglycerides and reduces the uptake of free fatty acids to the surrounding tissue. Recent advances in understanding ANGPTL4 function suggest that intestinal secretion of ANGPLT4 may reduce pancreatic lipase activity, [9] which is responsible for the hydrolysis of dietary triacylglycerides to monoacylglycerides and free fatty acids, making these available for absorption by the intestinal tissue. Therefore, increased levels of ANGPTL4 may reduce dietary fat uptake and thus increase excretion of fat with feces [9], suggesting that ANGPTL4 could function as a negative feedback mechanism on fat uptake. In addition, increased levels of ANGPTL4 in plasma may have beneficial effects on weight loss [10], diabetes [11] and atherosclerosis [12].

Amongst the fatty acids studied, butyrate has been found to be a potent inducer of intestinal ANGPTL4 gene expression and protein secretion [13, 14]. The butyrate level is high in the colon, resulting from bacterial fermentation of undigested polysaccharides; but, dietary sources such as milk also make butyrate available for uptake by cells lining the intestinal wall. Though butyrate has been extensively studied in different intestinal cell lines, current information on release of ANGPTL4 to the apical and basolateral side of the intestine after exposure is unavailable. The present study aims to investigate the release of ANGPTL4 to either side of the intestinal epithelial layer in a time-dependent manner in order to indicate possible modes of action upon intestinal induction of the ANGPTLA gene.

\section{METHODS:}

Cell Culture: Human intestinal Caco-2 (ATCC, HBT-37) cells were cultured in $75 \mathrm{~cm}^{2}$ flasks in $25 \mathrm{~mL}$ culture medium containing Dulbecco's Modified Eagle Medium, 10\% foetal bovine serum (Gibco), $1 \%$ penicillin/streptomycin (Gibco) and 1\% non-essential amino acids (Gibco). Cells were seeded on permeable membranes $(0.4 \mu \mathrm{m}$ PCF, Millicell) and placed in a 24 well plate at a density of $6.5 \times 10^{4}$ cells $\mathrm{cm}^{-2}$ with $800 \mu \mathrm{l}$ culture medium on the basolateral side and $400 \mu \mathrm{l}$ on the apical side. After two days the cells were confluent and left for spontaneous differentiation over 21 days, with regular change of culture medium approximately every second day. After the 21 days the culture medium was changed and transepithelial resistance (TER) values were measured twice across each permeable membrane and a mean TER was calculated (TER = ( $($ experimental medium $-\Omega$ control medium $) \times \mathrm{cm}^{2}$ ). The $\Omega$ control medium was the $\Omega$ value across a filter membrane with culture medium on both sides, but no cells. Only monolayers with TER values above $300 \Omega \mathrm{cm}^{2}$ were used for experiments [15]. 
Time Experiments: Culture medium was changed on the apical side to experimental medium consisting of $9 \mathrm{mM}$ sodium butyrate (Sigma-Aldrich) dissolved in cell culture medium, and incubated for different times ( $1 \mathrm{~h}, 2 \mathrm{~h}, 3 \mathrm{~h}, 6 \mathrm{~h}, 18 \mathrm{~h}, 21 \mathrm{~h}$ and $24 \mathrm{~h})$ at $37{ }^{\circ} \mathrm{C}$ and $5 \% \mathrm{CO}_{2}$.

Negative Feedback Experiments: $0.25 \mathrm{ng} / \mathrm{ml}$ recombinant human ANGPTL4 (3485-AN, R\&D Systems) (concentration based on realistic secretion levels obtained in the present study) was added to culture medium with or without $9 \mathrm{mM}$ sodium bytyrate on the apical side, or to the culture medium on the basolateral side. Cells were incubated at $37^{\circ} \mathrm{C}$ and $5 \% \mathrm{CO}_{2}$ for $24 \mathrm{~h}$ in order to study the effects of ANGPTL4 on ANGPTL4 gene expression and protein secretion.

Upon completion of the experiments, the experimental medium from the apical side and the culture medium with or without recombinant ANGPTL4 from the basolateral side was collected for analysis of ANGPTL4 protein concentration. The collection of media cells were then lysed with $350 \mu \mathrm{l}$ lysis buffer (RNeasy Mini Kit, Qiagen, Copenhagen, Denmark) and RNA was purified according to manufacturer's instructions.

Besides TER values, the integrity of the Caco-2 monolayer was validated with the fluorescent dye (lucifer yellow), which was incubated with the experimental medium on the apical side. After the experiment, the medium on both sides of the permeable membrane was analysed for lucifer yellow content. Absence of lucifer yellow on the basolateral side indicated an intact monolayer of cells throughout the experiment [15]. In the present study lucifer yellow at the basolateral side ranged from $2.3 \%$ to $6 \%$ with an average of $3.03 \%$ and standard deviation of $0.60 \%$. Cell viability was tested using WST-1 (Roche Hvidovre, Denmark), and the $9 \mathrm{mM}$ butyrate had no harmful effect on cells.

ELISA: ANGPTL4 levels in experimental and culture medium was determined using a sandwich ELISA protocol as described by Kersten et al [6], with minor modifications. Samples were prepared by adding $25 \mu 110 \times$ TBS to $225 \mu \mathrm{l}$ cell culture medium from Caco- 2 cells. $100 \mu 1$ of samples and standards (recombinant human ANGPTL4; 3485-AN, R\&D Systems) prepared in TBS containing $0.1 \%$ BSA was applied on anti-ANGPTL4 coated ELISA plates $(1.6 \mu \mathrm{g} / \mathrm{ml}$ polyclonal goat IgG in $0.1 \mathrm{M}$ bicarbonate/carbonate buffer, AF3485, R\&D Systems) for two hours at room temperature. After washing the plate thoroughly with 1 x PBS containing $0.1 \%$ Tween 20, samples were incubated with a biotinylated anti-ANGPTL4 detection antibody (0.8 $\mu \mathrm{g} / \mathrm{ml}$ polyclonal goat IgG; BAF3485; R\&D Systems) for two hours at room temperature. After another washing step, $100 \mu \mathrm{l}$ of streptavidin-horseradish peroxidase (1:200, DY998, R\&D Systems) was added to each well for 20 minutes, followed by incubation with TMB solution for 10 minutes. The reaction was stopped by adding $\mathrm{H}_{2} \mathrm{SO}_{4}(0.2 \mathrm{M})$ and absorbance was measured at $450 \mathrm{~nm}$ on a microtiter plate spectrophotometer (Synergy 2, Bio-Tek). The ANGPTL4 concentration was determined by interpolation to the concentrations of the standard solutions ranging from $0.0 \mathrm{ng} / \mathrm{ml}$ to $0.9 \mathrm{ng} / \mathrm{ml}$, after subtraction of either background absorbance or absorbance from $0.25 \mathrm{ng} / \mathrm{ml}$ ANGPTL4 in culture medium, with or without $9 \mathrm{mM}$ sodium byturate. The range of the assay was approximately $0.05-1.0 \mathrm{ng} / \mathrm{ml}$.

Real-time qPCR: $500 \mathrm{ng}$ total RNA was reverse transcribed using iScript ${ }^{\circledR}$ (Biorad, 
Copenhagen, Denmark) and real-time qPCR housekeeping gene. Data analysis was performed as previously described [16] to estimate the relative ANGPTLA mRNA levels in Caco-2 cells. The sequences of forward primers, reverse primers and hydrolysis probes were as follows: Human ANGPTL4; 5'GACCCGGCTCACAATGTCA'3， 5'ATCTTGCAGTTCACCAAAAATGG'3 and 5'TGCACCGGCTGCCCAGGG'3, $\beta$-actin; 5'- ACCCAGATCATGTTCGAGACCTT-3', 5'- TCACCGGAGTCCATCACGAT-3', 5’- CTGTATGCCTCTGGCCGCACCA-3’.

Statistical Analysis: The statistical analysis was carried out using the statistical software R version 2.14.0. An ANOVA test with Tukey's HSD Post Hoc test was used to test for significant different values between treatments. The level of significance was defined as $\mathrm{P}<0.05$.

\section{RESULTS:}

Caco-2 cells were incubated 21 days to spontaneously differentiate and create an intact monolayer after which caco-2 cells were incubated with $9 \mathrm{mM}$ butyrate for $1 \mathrm{~h}, 2 \mathrm{~h}, 3 \mathrm{~h}, 6 \mathrm{~h}, 18$ $\mathrm{h}, 21 \mathrm{~h}$ and $24 \mathrm{~h}$, respectively. The constitutive level of ANGPTL4 mRNA expression (control cells harvested at the same time) was slightly increased with time; but, the expression of butyrate exposed cells was significantly higher than the constitutive expression at 2-24 h of exposure. The level of ANGPTL4 mRNA was 3-4 fold increased after 2-3 h and 8-10 fold increased after 6-24 h incubation with butyrate. The constitutive expression was increased by 2-4 fold after 6-24 h which indicated an effective butyrate induction of ANGPTL4 by approximately 6-7 fold (Fig. 1).

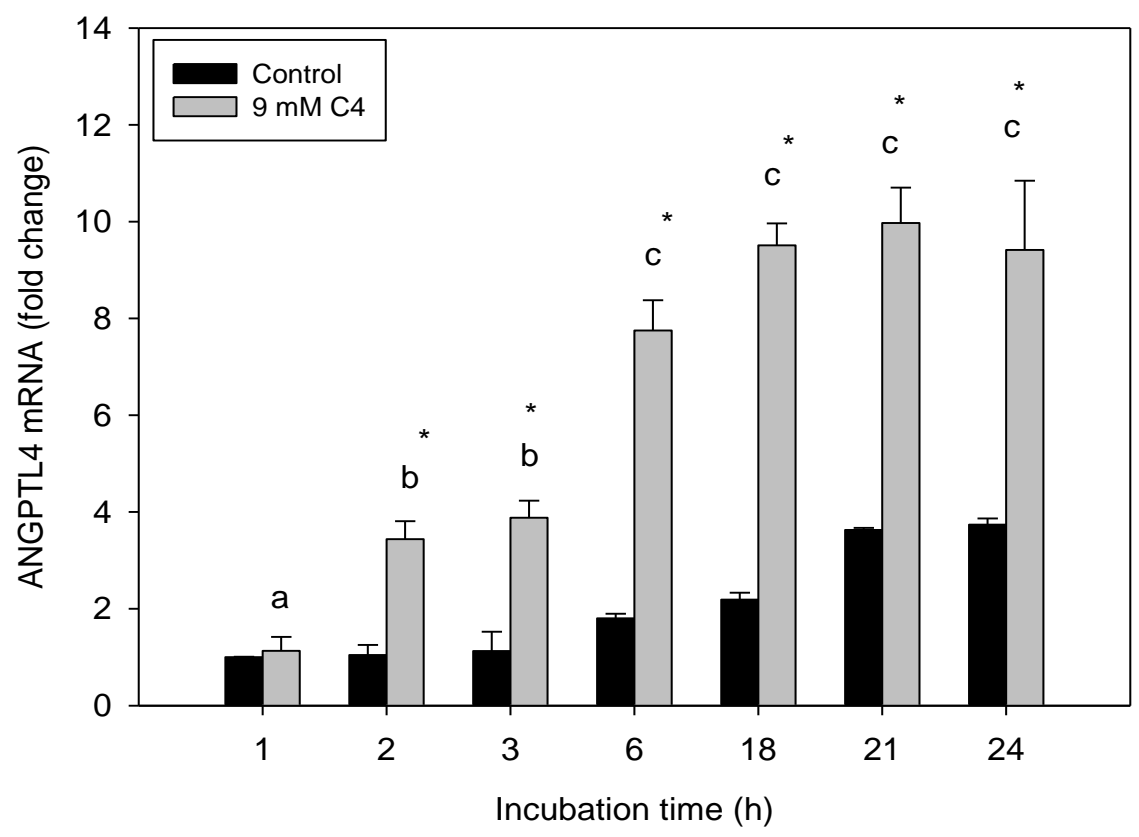

Figure 1: Butyrate induced ANGPTL4 gene expression. ANGPTL4 gene expression of differentiated Caco- 2 cell grown on permeable membranes after treatment with butyrate $(9 \mathrm{mM})$ for $1 \mathrm{~h}, 2 \mathrm{~h}, 3 \mathrm{~h}, 6 \mathrm{~h}, 18 \mathrm{~h}$ and $24 \mathrm{~h}$. Results are shown as means $\pm \mathrm{SE}, \mathrm{n}=3$. Different letters indicate significant different values between butyrate treated cells and asterisks (*) indicate significant difference between the treated cells and their respective control cells $(\mathrm{P}<0.05)$. 
Constitutive secretion of ANGPTL4 protein was slightly increased with time; but, an approximate two fold increase was observed from both the apical (Fig. 2A) and basolateral (Fig. 2B) side after 18-24 $\mathrm{h}$ of butyrate exposure.

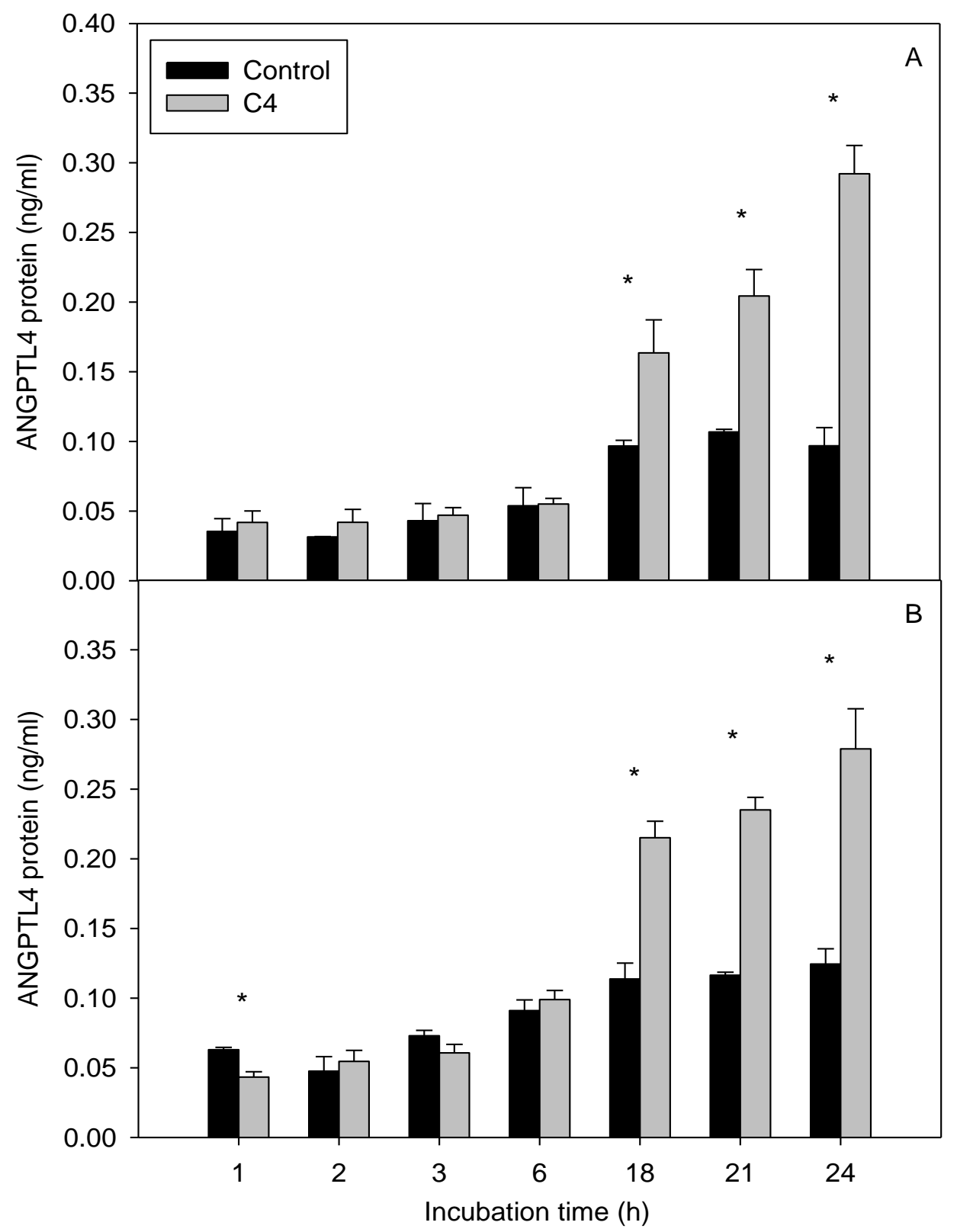

Figure 2: Butyrate induced ANGPTL4 protein secretion. ANGPTL4 protein section to the apical (A) and basolateral (B) side of differentiated Caco-2 cells (on permeable membranes) after treatment with butyrate $(9 \mathrm{mM})$ for $1 \mathrm{~h}, 2 \mathrm{~h}, 3 \mathrm{~h}, 6 \mathrm{~h}, 18 \mathrm{~h}$ and $24 \mathrm{~h}$. Results are shown as means $\pm \mathrm{SE}, \mathrm{n}=3$. Asterisks $\left({ }^{*}\right)$ indicate secretion different from the control at the respective time point $(\mathrm{P}<0.05)$.

The effect of adding recombinant ANGPTL4 protein to either the apical or basolateral side of the Caco-2 monolayer on both ANGPTL4 gene expression and protein secretion was investigated. 
The ANGPTL4 gene was induced by butyrate exposure but was not affected by the presence of recombinant ANGPTL4 protein at either the apical or basolateral side (Fig. 3).

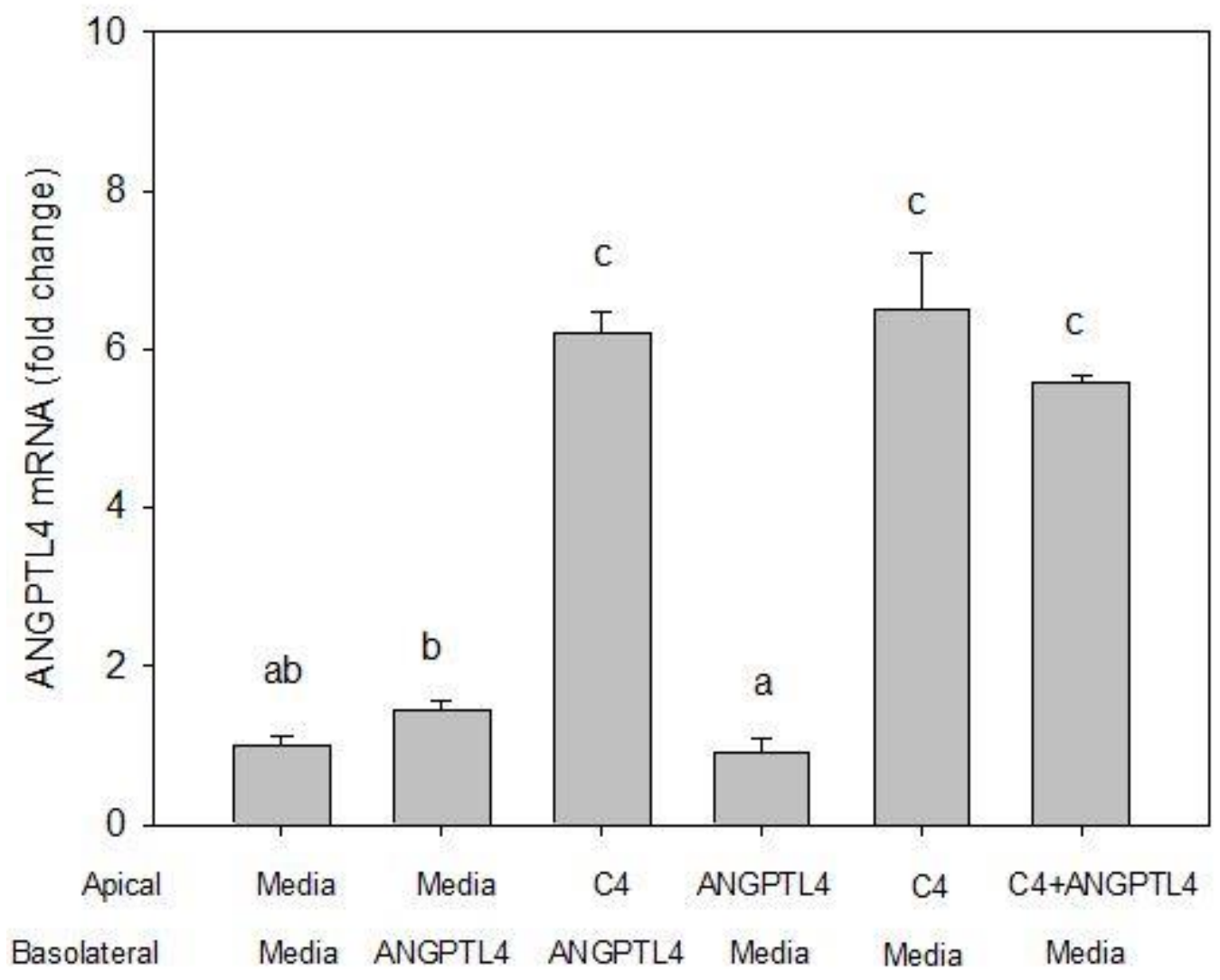

Figure 3: Recombinant ANGPTL4 protein feedback on apical and basolateral ANGPTL4 gene expression. ANGPTL4 gene expression of differentiated Caco-2 cells (on permeable membranes) after exposing the cells to $0.25 \mathrm{ng} / \mathrm{ml}$ recombinant human ANGPTL4 to the apical and basolateral sides (as indicated below the bars) for $24 \mathrm{~h}$. Results on constitutive ANGPTL4 expression (media on one side and ANGPTL4 protein on the other) and butyrate $(9 \mathrm{mM})$ induced expression are shown as means $\pm \mathrm{SE}, \mathrm{n}=3$. Different letters indicate significantly different expression $(\mathrm{P}<0.05)$.

Protein secretion to both sides of the cell monolayer was stimulated by butyrate exposure, but the presence of the ANGPTL4 protein to both the apical and basolateral sides affected the secretion. When adding the recombinant ANGPTL4 protein to the basolateral side, both the constitutive and the butyrate-induced secretion of ANGPTL4 protein to the basolateral side were reduced while the secretion to the apical side was unaffected (fig. 4). The values in fig. 4 show only the secreted protein as the added recombinant protein concentration was subtracted. This correction resulted in a negative value for constitutive basolateral secretion which merely shows that the recombinant ANGPTL4 protein degradation was greater than the newly secreted ANGPTL4 protein. However, when adding the recombinant ANGPTL4 protein to the apical side only the butyrate-induced apical secretion was reduced (fig. 5). Secretion to the basolateral side was not affected by addition of recombinant ANGPTL4 to the apical side. 


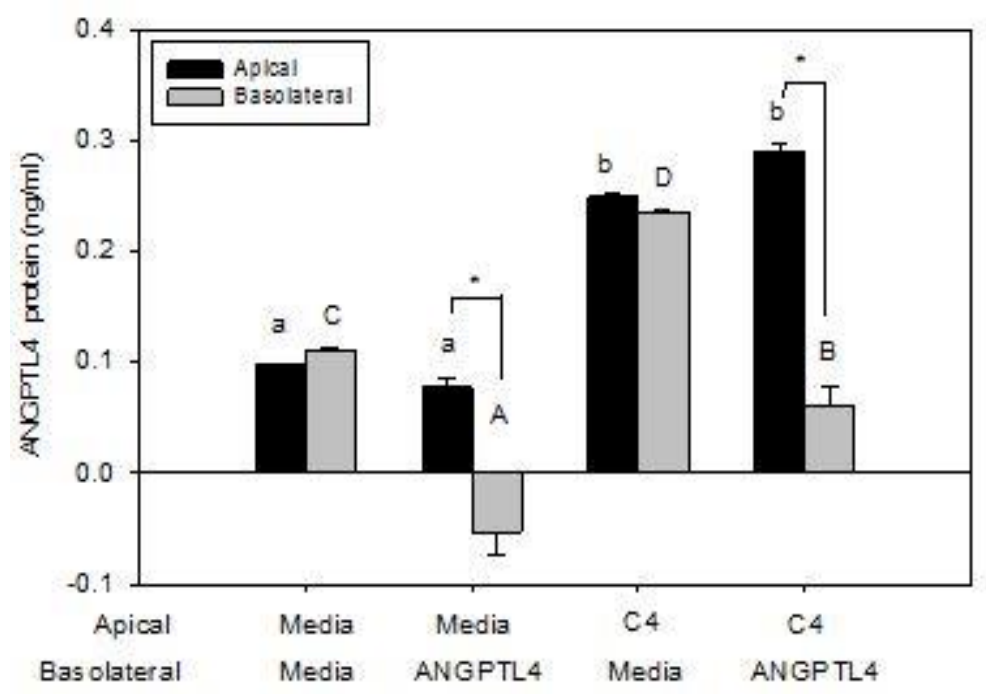

Figure 4: Apical and basolateral ANGPTL4 secretion upon basolateral exposure to ANGPTL4. ANGPTL4 protein secretion to the apical and basolateral side of differentiated Caco-2 cells (on permeable membranes) after exposing the cells to $0.25 \mathrm{ng} / \mathrm{ml}$ recombinant human ANGPTL4 to the basolateral side for $24 \mathrm{~h}$. Results on constitutive ANGPTL4 secretion (media on apical side) and butyrate $(9 \mathrm{mM})$ induced secretion are shown as means $\pm \mathrm{SE}, \mathrm{n}=2$. Different lower and upper case letters indicate significantly different secretion to the apical and basolateral sides, respectively. Asterisks (*) indicate different secretion to apical and basolateral sides $(\mathrm{P}<0.05)$.

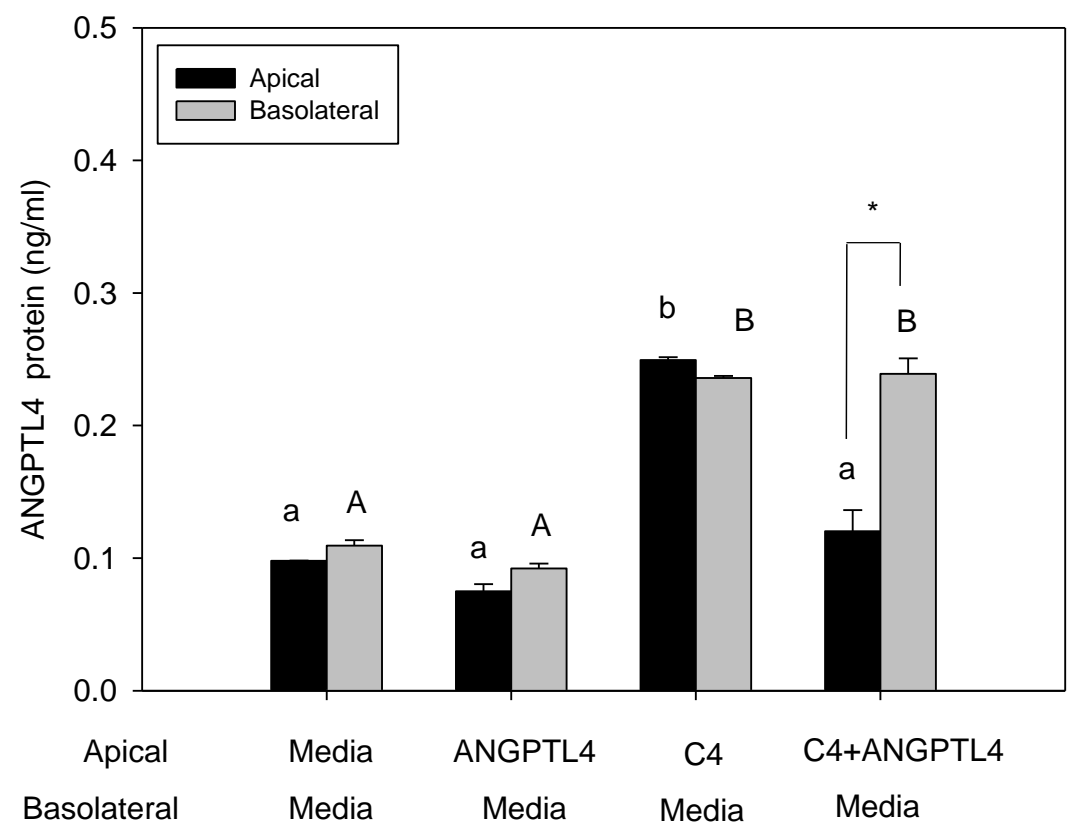

Figure 5: Apical and basolateral ANGPTL4 secretion upon apical exposure to ANGPTL4. ANGPTL4 protein secretion to the apical and basolateral side of differentiated Caco-2 cells (on permeable membranes) after exposing the cells to $0.25 \mathrm{ng} / \mathrm{ml}$ recombinant human ANGPTL4 to the apical side for $24 \mathrm{~h}$. Results on constitutive ANGPTL4 secretion (media on apical side) and butyrate (9 mM) induced secretion are shown as means $\pm \mathrm{SE}, \mathrm{n}=2$. Different lower and upper case letters indicate significantly different secretion to the apical and basolateral sides, respectively. Asterisks (*) indicate different secretion to apical and basolateral sides $(\mathrm{P}<0.05)$. 


\section{DISCUSSION:}

Short chain fatty acids produced by bacterial fermentation in the colon have been associated with the beneficial effects of dietary fibres. More specifically, butyrate has been suggested to have positive effects on obesity-related metabolic diseases [17]. ANGPTL4 expression has been suggested as a factor linking the intestinal microbiota to fat storage in adipose tissue [18]. Among the short chain fatty acids released from bacterial fermentation, previous studies have shown that butyrate was the most potent inducer of ANGPLT4 gene expression and protein secretion [13].

In the present study the increased ANGPLT4 gene expression correlated well with the increased ANGPTL4 protein secretion as ANGPTL4 gene expression reached its maximum after $6 \mathrm{~h}$ of butyrate exposure, followed by a significant increase of the protein secretion after 18-24 h. ANGPTL4 protein is secreted to both the apical and basolateral side. Basolateral secretion of ANGPTL4 protein could potentially function as endocrine regulation of LPL, as LPL is only expressed in very low levels in the intestinal tissue [19]. Hence, the released ANGPTL4 protein may be circulated with the blood and inhibit LPL in tissue with high expression of this enzyme [19]. Previously, Bäckhed and colleagues suggested that intestinal induced gene expression of ANGPTL4 could result in the inhibition of adipose tissue associated LPL activity [18]. Furthermore, increased plasma levels of ANGPTL4 have been associated with beneficial effect on atherosclerosis, diabetes $[11,20]$ and obesity $[10,21]$.

Suppression of both the constitutive and butyrate-induced basolateral secretion of ANGPTL4 protein after basolateral addition of recombinant ANGPTL4 protein suggest a negative feedback mechanism, potentially reducing the inhibition of LPL in an in vivo situation and thereby increasing the clearance of circulating triglycerides. A similar negative feedback was observed for the apical secretion where only the butyrate-induced ANGPTL4 protein secretion was reduced which, in an in vivo situation, would result in a reduced inhibition of pancreatic lipase and hence increased release of free fatty acids from dietary fat.

Dietary intake of butyrate containing food items (like milk) may be able to induce ANGPTL4 in the small intestine where both apical and basolateral secretion are relevant, whereas fermentation of dietary fibres causing high colonic levels of butyrate [22] seems only relevant for basolateral release.

\section{CONCLUSION:}

The effective butyrate-induced ANGPTL4 gene is increased 6 fold after $6 \mathrm{~h}$ followed by protein secretion after $18 \mathrm{~h}$ from both the basolateral and apical side of a Caco- 2 mono layer. In an in vivo context the butyrate-induced ANGPTL4 protein secretion initially suggests a suppression of the clearance of circulating triglycerides and secondly as a reduced fat uptake as consequences of basolateral and apical ANGPTL4 secretion, respectively. Collectively, this suggests that ANGPTL4 could play a contributory role in alleviating symptoms that can be associated with obesity.

List of Abbreviations Used: ANGPTL4, angiopoietin-like 4; LPL, lipoprotein lipase; TER, transepithelial resistance 
Competing Interests: The authors have no competing interests or conflicts of interest.

Authors' Contribution: All authors contributed in the idea generating phase and planning of the experiments. Randi Jessen carried out the experimental work, Søren Drud Nielsen wrote the first draft of the manuscript and all authors contributed to the interpretation of results, final discussion and wording of the manuscript.

\section{Acknowledgements and Funding:}

The study was supported by The Danish Council for Strategic Research, Arla Foods and the Danish Dairy Research Foundation in the project: "FIAF - Milk in Regulating Lipid Metabolism and Overweight: Uncovering Milk's Ability to Increase Expression and Activity of Fastinginduced Adipose Factor" with the journal number 10-093539.

\section{REFERENCES:}

1. Wyatt SB, Winters KP, Dubbert PM. Overweight and obesity: Prevalence, consequences, and causes of a growing public health problem. Am J Med Sci. 2006, 331(4):166-74.

2. Keys A, Parlin RW. Serum cholesterol response to changes in dietary lipids. The American journal of clinical nutrition. 1966, 19(3):175-81.

3. Siri-Tarino PW, Sun Q, Hu FB, Krauss RM. Meta-analysis of prospective cohort studies evaluating the association of saturated fat with cardiovascular disease. Am J Clin Nutr. 2010, 91(3):535-46.

4. Siri-Tarino PW, Sun Q, Hu FB, Krauss RM. Saturated fat, carbohydrate, and cardiovascular disease. Am J Clin Nutr. 2010, 91(3):502-9.

5. Astrup A, Dyerberg J, Elwood P, Hermansen K, Hu FB, Jakobsen MU, et al. The role of reducing intakes of saturated fat in the prevention of cardiovascular disease: where does the evidence stand in 2010? Am J Clin Nutr. 2011, 93(4):684-8.

6. Kersten S, Lichtenstein L, Steenbergen E, Mudde K, Hendriks HFJ, Hesselink MK, et al. Caloric restriction and exercise increase plasma ANGPTL4 levels in humans via elevated free fatty acids. Arerioscl throm vas. 2009, 29(6):969-U466.

7. Yau MH, Wang Y, Lam KS, Zhang J, Wu D, Xu A. A highly conserved motif within the NH2-terminal coiled-coil domain of angiopoietin-like protein 4 confers its inhibitory effects on lipoprotein lipase by disrupting the enzyme dimerization. J Biol Chem. 2009, 284(18):11942-52.

8. Yin W, Romeo S, Chang S, Grishin NV, Hobbs HH, Cohen JC. Genetic variation in ANGPTL4 provides insights into protein processing and function. J Biol Chem. 2009, 284(19):13213-22.

9. Mattijssen F, Alex S, Swarts HJ, Groen AK, M. van Schothorst E, Kersten S. Angptl4 serves as an endogenous inhibitor of intestinal lipid digestion. Molecular metabolism. 2013, 3(2):135-44. 
10. Robciuc MR, Naukkarinen J, Ortega-Alonso A, Tyynismaa H, Raivio T, Rissanen A, et al. Serum angiopoietin-like 4 protein levels and expression in adipose tissue are inversely correlated with obesity in monozygotic twins. J Lipid Res. 2011, 52(8):1575-82.

11. Xu A, Lam MC, Chan KW, Wang Y, Zhang J, Hoo RL, et al. Angiopoietin-like protein 4 decreases blood glucose and improves glucose tolerance but induces hyperlipidemia and hepatic steatosis in mice. Proc Natl Acad Sci USA. 2005, 102(17):6086-91.

12. Georgiadi A, Wang Y, Stienstra R, Tjeerdema N, Janssen A, Stalenhoef A, et al. Overexpression of angiopoietin-like protein 4 protects against atherosclerosis development. Short-chain fatty acids stimulate angiopoietin-like 4 synthesis in human colon adenocarcinoma cells by activating peroxisome proliferator-activated receptor gamma. Mol Cell Biol. 2013, 33(7):1303-16.

13. Alex S, Lange K, Amolo T, Grinstead JS, Haakonsson AK, Szalowska E, et al. Shortchain fatty acids stimulate angiopoietin-like 4 synthesis in human colon adenocarcinoma cells by activating peroxisome proliferator-activated receptor gamma. Mol Cell Biol. 2013, 33(7):1303-16

14. Korecka A, de Wouters T, Cultrone A, Lapaque N, Pettersson S, Dore J, et al. ANGPTL4 expression induced by butyrate and rosiglitazone in human intestinal epithelial cells utilizes independent pathways. Am J Physiol-Gastr L. 2013, 304(11):G1025-G37.

15. Hubatsch I, Ragnarsson EGE, Artursson P. Determination of drug permeability and prediction of drug absorption in Caco-2 monolayers. Nat Protoc. 2007, 2(9):2111-9.

16. Nielsen SD, Young JF, Mortensen G, Petersen RK, Kristiansen K, Dalsgaard TK. Activation of the angiopoietin-like 4 (ANGPLT4) gene by milk fat and casein. Int Dairy J. 2014, 36(2):136-42.

17. Brahe LK, Astrup A, Larsen LH. Is butyrate the link between diet, intestinal microbiota and obesity-related metabolic diseases? Obesity Reviews. 2013, 14(12):950-9.

18. Bäckhed F, Ding H, Wang T, Hooper LV, Koh GY, Nagy A, et al. The gut microbiota as an environmental factor that regulates fat storage. P Proc Natl Acad Sci USA. 2004, 101(44):15718-23.

19. Dijk W, Kersten S. Regulation of lipoprotein lipase by Angptl4. Trends Endocrin Met. 2014, 25(3):146-55.

20. Chong HC, Chan JS, Goh CQ, Gounko NV, Luo B, Wang X, et al. Angiopoietin-like 4 stimulates STAT3-mediated iNOS expression and enhances angiogenesis to accelerate wound healing in diabetic mice. Mol Ther. 2014.

21. Kim HK, Youn BS, Shin MS, Namkoong C, Park KH, Baik JH, et al. Hypothalamic angptl4/fiaf is a novel regulator of food intake and body weight. Diabetes. 2010, 59(11):2772-80.

22. Haenen D, Zhang J, da Silva CS, Bosch G, van der Meer IM, van Arkel J, et al. A diet high in resistant starch modulates microbiota composition, SCFA concentrations, and gene expression in pig intestine. J Nutr. 2013, 143(3):274-83. 